\title{
WELFARE REDUCING LICENSING
}

\author{
Ramón Faulí-Oller and J oel Sandonís
}

WP-AD 2000-12

Correspondence to J. Sandonís: Universidad del País Vasco. Departamento de Fundamentos del Análisis Económico. Avd. Lehendakari Aguirre 83, 48015 Bilbao. Spain. e-mail: jepsadij@bs.ehu.es.

Editor: Instituto Valenciano de Investigaciones E conómicas, s.a.

First Edition J une 2000.

Depósito Legal: V-2093-2000

IVIE working papers oxer in advance the results of economic research under way in order to encourage a discussion process before sending them to scienti..c journals for their ..nal publication.

* This paper has been partially written while the second author was visiting the Kellogg Graduate School of Management at Northwestern University. We would like to thank Bruno Cassiman, Stephen Martin, David Pérez-Castrillo and an anonymous referee from the IVIE for useful suggestions. Financial support from projects DGES PB97-0603, UPV 035.321-HB 159/ 98 (Sandonís), CICY T PB 97-0131 and the IVIE (Faulí-Oller) is gratefully acknowledged.

* R. Faulí-Oller: Universidad de Alicante. J . Sandonís: Universidad del País Vasco. 


\title{
WELFARE REDUCING LICENSING
}

\author{
Ramón Faulí-Oller and J oel Sandonís
}

\section{A B STR A C T}

In this paper, we characterize situations where licensing an innovation to a rival ..rm using two-part tarix contracts (a ..xed fee plus a linear per unit of output royalty) reduces social welfare. We show that it occurs if and only if i) the goods are close enough substitutes, ii) the innovation is large enough but not drastic and iii) the ..rms compete in prices. Moreover, we show that, regardless of the type of competition, ..rst, the optimal contract always includes a positive royalty and, second, even drastic innovations are licensed whenever the goods are not homogeneous.

Keywords: Two-part tariæ contracts, licensing

JEL Classi..cation: D45 


\section{INTRODUCTION}

The theoretical literature on licensing has mainly focused on comparing and analyzing the performance of both ..xed fees and royalties as instruments to license cost-reducing innovations. Empirical evidence reports the use of both types of instruments, legitimating economists to look for the conditions under which one instrument is preferred to the other. For example, Rostocker (1984) ..nds that royalty alone is used $39 \%$ of the time, ..xed fee alone $13 \%$ and both instruments together $46 \%$. Calvert (1964), Taylor and Silberston (1973) and Macho-Stadler et al. (1996) report similar percentages. Tipically, the fact that most of the contracts include both instruments together is explained in literature by the existence of either asymmetric information or uncertainty. In the ..rst case, the use of royalties allows the patentee either to signal good innovations or to separate the potential licensees that are willing to pay more for the innovation (M acho-Stadler and Pérez-Castrillo (1991), MachoStadler et al.(1996), Gallini and Wright (1990) and Hornsten (1998)). In the second case, risk sharing is the reason to include a royalty in the contract (this idea has been recently formalized by Bousquet et al. (1998)). However, in the context of perfect and complete information and with two notable exceptions, no paper has investigated optimal two-part tarix contracts. Those two exceptions are Kamien and Tauman (1984), that focus on the case of linear royalties based on output and E rutku and Richelle (2000), that extend Kamien and Tauman (1986) to two-part tarix contracts including non-linear royalties based either on output or in sales. Both articles analyze the case of an external to the industry patentee selling the innovation to a Cournot oligopoly.

In the present work, in a perfect and complete information setting, the optimal two-part tarix contract ( $a$..xed fee plus a linear, per unit of output royalty) to license a patented cost reducing innovation is derived in a dixerentiated goods Bertrand and Cournot duopoly for the case in which the patentee is himself a producer in the industry. On the one hand, we obtain that, regardless of the type of competition, ..rst, the optimal contract always includes a royalty, very often accompanied by a fee. The royalty is used to increase the licensee's marginal costs, softening in that way ex-post competition, and the fee to extract the increase 
in industry pro..ts generated by the use of the superior technology. Second, whenever the goods are not homogeneous, even drastic innovations are licensed in equilibrium. The reason is that licensing a drastic innovation allows the patentee to keep open a pro..table market for the other brand, and the royalty revenues more than compensate her for the increase in market competition.

Furthermore, under Bertrand competition, setting a positive royalty allows the patentee not only to control the licensee's marginal cost but also to strategically commit herself to a less aggressive behavior in the market, as the licensing revenues become increasing in her price decision. We show that, for close enough substitute goods and large enough innovations (but not drastic), licensing the superior technology leads to a decrease in social welfare. This collusive exect does not arise, however, in the Cournot model, where the licensing revenues do not depend on the patentee's decision on output. Obviously, it would not arise either, in the case of an external to the industry patentee. ${ }^{1}$

A mong the theoretical works on licensing, in a perfect and complete information setting and for the case of an external to the industry patentee, in addition to the previously quoted Kamien and Tauman (1984) and Erutku and Richelle (2000), Kamien and Tauman (1986) and $\mathrm{K}$ atz and Shapiro (1986) show, ..rst, that licensing by means of a fee is superior to licensing by means of a royalty, in a homogeneous goods Cournot oligopoly and, second, in that setting, auctioning a ..xed number of licenses is superior to ..xed fee licensing. An excellent survey on the licensing literature can be found in Kamien, 1992. Muto (1993) extends those works to the case of B ertrand competition and shows that for the case of close substitute goods a royalty can be superior to a fee.

For the case of a patentee that is himself a producer in the industry, Katz and Shapiro (1985) analyze ..xed fees in a homogeneous goods Cournot duopoly and show that, for large enough innovations, licensing becomes non-pro..table for the patentee. Wang (1998) extends

\footnotetext{
${ }^{1}$ Erutku and Richelle (2000), for the case of an external to the industry patentee, show that by using two-part tarix contracts that include non-linear royalties based on sales, an external patentee can always design a sophisticated contract that allows her to get the monopoly pro..ts, leading the licensees' pro..ts to zero. They show that, in that framework, licensing small innovations reduces social welfare.
} 
their analysis to the comparison between ..xed fees and royalties and shows that, for the case of homogeneous goods, a royalty is always superior to a fee. Our paper can be seen as a natural extension of Wang's paper to the case of two-part tarix contracts applied to the case of dixerentiated goods and not only to Cournot but also to Bertrand competition.

The article is organized as follows: next section presents the model. Section 3 solves the game for the case of B ertrand competition and characterizes the circumstances under which licensing reduces social welfare. Section 4 extends the analysis to Cournot competition. We conclude in Section 5. 


\section{THE MODEL}

We consider two ..rms, denoted by $\mathrm{i}=1 ; 2$, each producing a dixerentiated good (goods 1 and 2 respectively). They face inverse demand functions given by:

$$
p_{i}=a_{i} \quad x_{i} i{ }^{\circ} x_{j} ; i ; j=1 ; 2 ; i \in j
$$

where $a>0$ and ${ }^{\circ} 2[0 ; 1]$ represents the degree of product dixerentiation. These demands are derived from the maximization problem of a representative consumer (see Singh and Vives 1984), endowed with a utility function separable in money (denoted by $\mathrm{m}$ ) given by:

$$
u\left(x_{1} ; x_{2}\right)=a\left(x_{1}+x_{2}\right) ; \frac{x_{1}^{2}}{2} i \frac{x_{2}^{2}}{2} i{ }^{\circ} x_{1} x_{2}+m
$$

The direct demand functions are given by:

$$
x_{i}=\frac{a}{1+{ }^{\circ}} i \frac{p_{i}}{1 i^{\circ 2}}+{ }^{\circ} \frac{p_{j}}{1 i^{\circ}} ; i ; j=1 ; 2 ; i \in j:
$$

Firm 2 has constant unit production costs of c: Firm 1 is assumed to have a patented process innovation that allows the production of both good 1 and (eventually) good 2 at a lower marginal cost that we assume for convenience and, without loss of generality, to be zero. Therefore, c can be interpreted also as the size of the innovation. Following Arrow (1962), and depending on its size, we distinguish between drastic and non-drastic innovations. We call an innovation drastic when the owner may monopolize its market, that is, when the monopoly price under the innovation is lower than $c$. In particular, this is the case if $c>c^{M}$; where $c^{M}=\frac{a\left(2_{i}{ }^{\circ}\right)}{2}$ :

Incorporating the fact that ..rm 1's marginal cost is assumed to be zero, let us de..ne the social welfare function as:

$$
W\left(x_{1} ; x_{2}\right)=u\left(x_{1} ; x_{2}\right) \text { i } c x_{2} \text { : }
$$

The timing of the game is the following: in the ..rst stage, the patentee oxers a contract to ..rm 2 in a takeit-or-leave-it basis. In the second stage, the potential licensee decides whether to accept or reject the contract. Finally, both ..rms compete in the market, either 
in prices (Section 3) or in quantities (Section 4). We look for the subgame perfect $N$ ash equilibrium of the proposed game, solving by backward induction. A contract is de..ned as a pair $(f ; r)$, where $f$ represents a ..xed fee and $r$ a per unit of output royalty. ${ }^{2}$

B efore solving the game, let us point out the main dixerence between the Cournot and Bertrand models, that will help the reader to understand the results. In the third stage of the game, under Cournot competition and if ..rm 2 has accepted a $(f ; r)$ contract, the ..rms solve respectively:

$$
\begin{aligned}
& M \operatorname{Mx}_{x_{1}} f p_{1}\left(x_{1} ; x_{2}\right) x_{1}+r x_{2} g \\
& M \operatorname{Mx}_{x_{2}} f p_{2}\left(x_{1} ; x_{2}\right) x_{2} i r x_{2} g
\end{aligned}
$$

where $\mathrm{p}_{\mathrm{i}}\left(\mathrm{x}_{1} ; \mathrm{x}_{2}\right) \mathrm{i}=1 ; 2$;denote ..rm i's inverse demand function. The ..rst order conditions are given by:

$$
\begin{gathered}
p_{1}+x_{1} \frac{\Phi_{1}}{@ x_{1}}=0 ; \\
p_{2}+x_{2} \frac{\Phi_{2}}{@ x_{2}} ; r=0:
\end{gathered}
$$

Changing the strategic variable from quantity to price adds an important new exect to the market competition stage: when choosing price, ..rm 1 considers not only its exect on own market pro..ts but also on ..rm 2's demand, that determines its royalty revenues. The program now becomes:

$$
\begin{aligned}
& M \operatorname{Mx}_{p_{1}} f p_{1} x_{1}\left(p_{1} ; p_{2}\right)+r x_{2}\left(p_{1} ; p_{2}\right) g ; \\
& M \operatorname{ax}_{p_{2}} f p_{2} x_{2}\left(p_{1} ; p_{2}\right) \text { i } r x_{2}\left(p_{1} ; p_{2}\right) g ;
\end{aligned}
$$

where $x_{i}\left(p_{1} ; p_{2}\right) ; i=1 ; 2$ denotes the direct demand functions. The ..rst order conditions are given by:

$$
\begin{aligned}
& x_{1}+p_{1} \frac{\Phi_{1}}{\Phi_{1}}+r \frac{\Phi_{2}}{\Phi_{1}}=0 \\
& x_{2}+p_{2} \frac{\Phi_{2}}{\Phi_{2}} ; r \frac{\Phi_{2}}{\Phi_{2}}=0
\end{aligned}
$$

\footnotetext{
${ }^{2} \mathrm{~N}$ otice that we do allow for contracts including negative royalties. Nevertheless, for the case of substitute goods, it is never optimal for an internal to the industry patentee to charge a negative royalty. This would be the case, however, for complementary goods, that are not considered in this work.
} 
Comparing the ..rst order conditions under Cournot and Bertrand competition, we can see that in the latter case, a new term appears in the ..rst equation (the third term) that provides the patentee with an additional incentive to behave less aggressively in the market: in that way, she increases ..rm 2's demand and thus her licensing revenues. Observe that the new exect is absent when ..rms choose quantities because, in that case, .rm 2's demand is not axected by the decision (on output) taken by ..rm 1. That is, under Bertrand competition, including a positive royalty in the contract allows the patentee not only to control the marginal cost of the licensee but also to commit herself to a higher price. 


\section{BERTRAND COMPETITION}

Let us ..rst analyze the case of non-drastic innovations $\left(c<c^{M}\right)$. The third stage $N$ ash equilibrium prices, outputs and pro..ts, when ..rm 2 has accepted a $(f ; r)$ contract with $r \cdot c$, are given by ${ }^{3}$ :

$$
\begin{aligned}
& p_{1}(r)=\frac{a\left(2 i^{\circ} i^{\circ 2}\right)+3^{\circ} r}{4 i^{\circ 2}} ; p_{2}(r)=\frac{a\left(2 i^{\circ} i^{\circ 2} 2\right)+\left(2+^{\circ 2}\right) r}{4 i^{\circ 2}} ; \\
& x_{1}(r)=\frac{a\left(2+^{\circ}\right) i^{\circ} r\left(1++^{\circ}\right)}{\left(1++^{\circ}\right)\left(4_{i}{ }^{\circ}\right)} ; x_{2}(r)=\frac{a\left(2+^{\circ}\right) i 2 r\left(1++^{\circ}\right)}{\left(1++^{\circ}\right)\left(4_{i}{ }^{\circ}\right)} ; \\
& 1 / 4(r)=p_{1}(r) x_{1}(r) ; 1 / \mathbb{Q}(r)=\left(p_{2}(r) ; r\right) x_{2}(r):
\end{aligned}
$$

It is easy to check that for low values of $r, @ / 4(r)=@ r>0 ; i=1 ; 2$, which implies that both ..rms are interested in setting a positive royalty in the contract. ${ }^{4}$ It is in this sense that we can say that the royalty works as a collusive device: it bene.ts to both ..rms.

On the other hand, if $r>c$, the new technology would not be used and the market stage would be as if no licensing agreement would have been signed (status quo). In that case and for $c<c^{p}$; where $c^{p}=\frac{a\left(2_{i}{ }^{\circ}{ }^{\circ}{ }^{\circ 2}\right)}{2 i^{\circ 2}}$; we would have the following equilibrium prices, outputs and pro..ts:

$$
\begin{aligned}
& P_{1}(c)=\frac{a\left(2 i^{\circ} i^{\circ 2}\right)+{ }^{\circ} c}{4 i^{\circ 2}} ; P_{2}(c)=\frac{a\left(2 i^{\circ} i^{\circ 2}\right)+2 c}{4 i^{\circ 2}} ;
\end{aligned}
$$

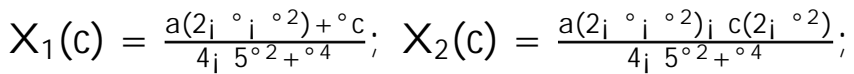

$$
\begin{aligned}
& { }_{1}(c)=P_{1}(c) X_{1}(c) ; i_{2}(c)=\left(P_{2}(c) ; c\right) X_{2}(c) \text { : }
\end{aligned}
$$

In this region, both ..rms are active.

If, on the other hand, $c^{\mathrm{P}} \cdot \mathrm{c}<\mathrm{c}^{\mathrm{M}}$, they are given by:

$$
\begin{gathered}
P_{1}(c)=\frac{a\left(i 1+^{\circ}\right)+c}{0} P_{2}(c)=c ; \\
X_{1}(c)=\frac{a i c}{0} ; X_{2}(c)=0 ; \\
{ }_{1}(c)=P_{1}(c) X_{1}(c) ; \quad{ }_{2}(c)=0:
\end{gathered}
$$

\footnotetext{
${ }^{3}$ In order to check that the interior equilibrium is exectively an equilibrium we have to check that no ..rm has an incentive to deviate by lowering its price in order to expel the competitor from the market. This would be the case only if $r>r^{M}=\frac{a\left(8+8^{\circ}+{ }^{\circ 3}+{ }^{\circ 4}+2 \overline{\left.16 i 24^{\circ 2}+9^{\circ 4} i^{\circ 6}\right)}\right.}{2\left(8+8^{\circ}+{ }^{\circ 2}+^{\circ 3}\right)}$. However, as $r^{M}>c^{M}$; the above expressions exectively represent the equilibrium for the non-drastic case.

${ }^{4}$ Strictly speaking, this would be the case only when no ..xed fee could be used in the contract. Otherwise, as we will see below, the patentee will choose a ..xed fee that makes the licensee indixerent between accepting or rejecting the contract.
} 
In this region, ..rm 2 is not active but ..rm 1 cannot charge the monopoly price. In the ..rst stage, ..rm 1 looks for the contract $(f, r)$ that solves:

$$
\begin{aligned}
& \max _{f ; r} f 1 / \mathbb{4}(r)+r x_{2}(r)+f g \\
& \text { s:t: } f \cdot 1 / \mathbb{Q}(r) \text { i } \\
& r \cdot 2(c) ;
\end{aligned}
$$

It is easy to check that the ..rst constraint is always binding, which implies that the previous program can be rewritten in the following way:

$$
\begin{aligned}
& \max _{f ; r} f^{1 / 41}(r)+r x_{2}(r)+1 / \mathbb{L}(r) ; \quad{ }_{2}(c) g \\
& \text { s:t: } r \cdot c:
\end{aligned}
$$

The solution to this program directly results in the following proposition:

Proposition 3.1. Under Bertrand competition, the optimal two-part tarix licensing contract is given by:

$$
\begin{aligned}
& r^{\not}=\operatorname{minf}_{B} ; c \text { cg; where } r_{B}=\frac{a^{\circ}\left(2+^{\circ}\right)^{2}}{2\left(4+5^{\circ 2}\right)} \text {; } \\
& f^{x}=1 / 4\left(r^{x)}\right) ; \quad \mid \quad 2(c):
\end{aligned}
$$

Notice that both the ..xed fee and the royalty are always positive under the optimal contract. This result is consistent with the empirical observation that most of the licensing contracts combine both instruments. Furthermore, the proposition also shows that the existence of asymmetric information or uncertainty is not necessary to justify the use of royalties. In our model, it arises only for purely strategic reasons. The patentee sets a positive royalty to soften ex-post market competition not only by raising the licensee's marginal cost but also by tying its own licensing revenues to the third stage decision on price. On the other hand, the ..xed fee is positive even when $r^{\not}=c$. The reason is that, even with the same marginal cost of production, ..rm 2's market pro..ts under licensing are higher than under the status quo, because she takes advantage of the less aggressive behavior of ..rm 1 induced by the contract.

Let us now analyze the case where the innovation is drastic $\left(c, c^{M}=\frac{a\left(2 i^{\circ}\right)}{2}\right)$. In this case, ...rm 1 has two possibilities: either not to license the technology and obtain market 1 
monopoly pro..ts or licensing the technology in the terms of Proposition 3.1. Observe that $r_{B}<C^{M}$ whenever the goods are not perfect substitutes, which means that if the innovation is licensed ..rm 2 will always be active. ${ }^{5}$ Next proposition compares the two alternatives.

P roposition 3.2. Whenever the goods are not perfect substitutes, even drastic innovations are licensed.

Proof. The proposition results from checking that the patentee's pro..ts of not licensing, $\left(\frac{\mathrm{a}^{2}}{4}\right)$ are lower than the ones obtained if technology is licensed in the terms of Proposition 3.1, $1 / 4\left(r_{B}\right)+r_{B} x_{2}\left(r_{B}\right)+1 / 1 / 4\left(r_{B}\right)$.

The intuition behind the result is clear: whenever the goods are not perfect substitutes, licensing a drastic innovation allows the patentee to keep open a (dixerent) pro..table market, and the royalty revenues more than compensate her for the increase in market competition.

We shall proceed now to the analysis of the welfare exects of licensing. Last proposition seems to suggest that the possibility of licensing should increase social welfare because the licensing mechanism allows the dixusion of all innovations, which implies a gain in el ciency produced by the use of the superior technology. However, this is obtained at the cost of allowing for the use of contracts that lead to higher prices in the market. Next proposition clari..es the trade-ox.

\footnotetext{
${ }^{5}$ For the particular case ${ }^{\circ}=1, r_{B}=c^{M}$. However, the above calculations cannot be applied to this case because demands are not de..ned. Anyway, it is easy to see that the best option for the patentee would be in that case not to license the superior technology.
} 
Proposition 3.3. For close enough substitute goods $\left({ }^{\circ}>0: 72\right)$, two threshold values for the size of the innovation (c) always exist such that for innovations lying within that interval, licensing reduces social welfare.

Proof. The result follows from comparing social welfare under licensing and under the status quo. For ${ }^{\circ} \cdot 0: 72$, the latter is never superior. For $0: 72<{ }^{\circ}<0: 94$, the status quo is superior if and only if $\mathrm{c}^{11}<\mathrm{c}<\mathrm{c}^{12}$ : Finally, if ${ }^{\circ}, 0: 94$ if and only if $\mathrm{c}^{13}<\mathrm{c}<\mathrm{c}^{12}$; where

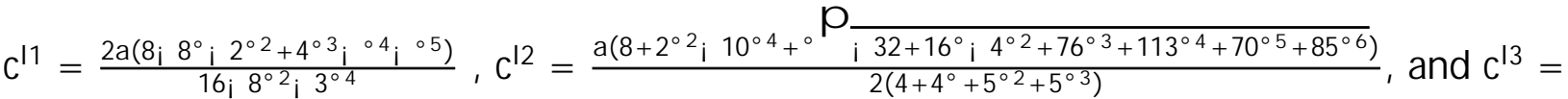

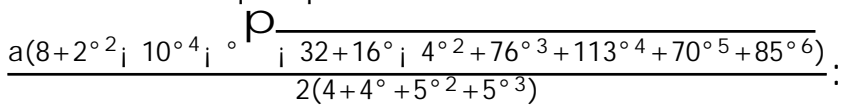

The intuition for the result is the following: consider the case $r=c$. Under Bertrand competition, the collusive exect of licensing leads to higher prices and thus lower outputs in equilibrium than in the status quo, even though ..rm 2's ..nal marginal cost of production is the same in both situations. For close enough substitute goods, the anticompetitive exect more than compensates the el ciency gain of licensing, thus reducing total welfare. However, as the innovation becomes larger, for near drastic innovations, licensing becomes again welfare superior to the status quo. Notice that for the extreme case of a drastic innovation, in absence of licensing we would have just a monopoly in market 1 , while under licensing we would have two duopoly markets because, as proved in Proposition 3.2, whenever the goods are not homogeneous even drastic innovations are licensed. Therefore, for drastic innovations (and by continuity also for near drastic innovations) licensing must be welfare superior to the status quo. Figure 1 plots the social welfare functions under the optimal licensing contract (WI) and under the status quo (W sq) as a function of c, for close enough substitute goods $\left({ }^{\circ}>0: 72\right)$. While the welfare function under licensing is decreasing whenever $c<r_{B}$ (notice that, in that case, the optimal royalty is $r^{\not}=c$ and, hence, it increases with $c$ ) and constant for $C, r_{B}$ (in that case, the optimal royalty is $r^{x}=r_{B}$ and it is constant in $C$ ), welfare under the status quo follows a more complex pattern: for $C<c^{P}$ it is convex, with 
an interior minimum, crossing once the licensing welfare function; ${ }^{6}$ for $c^{P} \cdot C<c^{M}$, it is decreasing and crosses again that function; ${ }^{7}$..nally, for $\mathrm{c}, \mathrm{c}^{\mathrm{M}}$ it is constant in $\mathrm{c}$. As Figure 1 shows, for intermediate values of $c$ the status quo is welfare superior to licensing.

\footnotetext{
${ }^{6} \mathrm{~N}$ otice that when ..rm 2 becomes very ined cient, by increasing its marginal costs, we allow the ef cient ..rm to produce extra units more ed ciently, at the cost of reducing the inet cient ..rm 2's activity, thus increasing welfare. This exect is captured in Figure 1 by the increasing part of the status quo welfare function.

${ }^{7}$ If $c^{P} \cdot c<c^{M}, . . r m 2$ is not active but ..rm 1 cannot charge the monopoly price. Increasing $c$ in this region can only reduce welfare because the ine cient ..rm cannot transfer ined cient units of output to ..rm 1, given that it cannot reduce output below zero. Therefore, its only exect is reducing the ed cient ..rm's output, thus reducing welfare.
} 


\section{COURNOT COMPETITION}

We start by calculating the third stage ..rms' Nash equilibrium outputs, prices and pro..ts, given that ..rm 2 has accepted a $(f ; r)$ contract, where $r$. c. They are given, respectively, by:

$$
\begin{gathered}
x_{1}(r)=\operatorname{minf} \frac{a\left(2 i^{\circ}\right)+{ }^{\circ} r}{4 i^{\circ 2}} ; \frac{a}{2} g ; x_{2}(r)=\operatorname{maxf} \frac{a\left(2 i^{\circ}\right) i 2 r}{4_{i}{ }^{\circ 2}} ; 0 g ; \\
p_{1}(r)=\operatorname{minf} \frac{a\left(2 i^{\circ}\right)+{ }^{\circ} r}{4 i^{\circ}{ }^{\circ}} ; \frac{a}{2} g ; p_{2}(r)=\operatorname{maxf} \frac{a\left(2 i^{\circ}\right)+\left(2 i^{\circ}\right) r}{4 i^{\circ 2}} ; r g ; \\
1 / 4(r)=x_{1}(r)^{2} ; 1 / 4(r)=x_{2}(r)^{2}:
\end{gathered}
$$

Observe that $@ / 4(r)=@ r>0$; while $@ / \Phi(r)=@<<0$, that is, under Cournot competition the royalty bene..ts the patentee but hurts the licensee. In this sense, we can say that the royalty is anticompetitive (it increases the licensee's marginal cost) but not collusive, as it was under Bertrand competition.

By substituting $\mathrm{c}$ for $\mathrm{r}$ in the above expressions, the equilibrium outputs, prices and pro..ts under the status quo are obtained. Notice that when ..rm 2 is not active, ..rm 1 produces the monopoly output $\mathrm{x}_{1}=\mathrm{a}=2$.

In the second stage of the game, ..rm 2 decides whether or not to accept the contract oxered by the patentee. It will accept any contract satisfying $f \cdot 1 / \mathbb{\Psi}(r)$ i $1 / \mathbb{\Psi}(c)$ : In the ..rst stage, ...rm 1 looks for the contract $(f, r)$ that solves:

$$
\begin{aligned}
& \max _{f ; r} f 1 / \mathbb{1}(r)+r x_{2}(r)+f g \\
& \text { s:t: } \quad f \cdot 1 / \mathbb{4}(r) \text { i } 1 / \mathbb{4}(c) \\
& r \cdot c
\end{aligned}
$$

This program can be written in a simpli..ed way. As the ..rst constraint is always binding, it can be substituted in the objective function. The maximization problem thus becomes:

$$
\begin{aligned}
& \max _{r} f 1 / \mathbb{4}_{1}(r)+r x_{2}(r)+1 / \mathbb{Q}_{2}(r) \text { i } 1 /{ }_{2}(c) g \\
& \text { s:t: } r \cdot c:
\end{aligned}
$$

The solution to this program directly results in the following proposition: 
Proposition 4.1. Under Cournot competition, the optimal two-part tarix licensing contract is given by:

$$
\begin{aligned}
& r^{\text {a }}=\operatorname{minf} c ; r_{c} g ; \text { where } r_{c}=\frac{a^{\circ}\left(2 i^{\circ}\right)^{2}}{2\left(4 j_{i} 3^{\circ 2}\right)} ; \\
& f^{x}=\max f^{1 / \mathbb{Q}}\left(r^{\natural}\right) ; \quad 1 / \mathbb{Q}(c) ; 0 g:
\end{aligned}
$$

Observe that the optimal contract always includes a positive royalty ${ }^{8}$. In that way, the patentee softens ex-post competition by raising the licensee's marginal cost of production. However, contrary to the B ertrand case, the royalty cannot be used by the patentee to commit herself to a less aggressive behavior in the market. This explains that in the particular case $r^{\not x}=c$, the licensee obtains the same market pro..t as under the status quo and, therefore, in order to be accepted, the contract cannot include a positive ..xed fee. The use of contracts including only a royalty is reported to be usual by the empirical existing literature. Our result justi..es the existence of that kind of contracts.

The following question would be when the patentee ..nds pro..table to license the innovation to the rival ..rm. Wang (1998), in his homogeneous goods Cournot duopoly model, showed that only non-drastic innovations are licensed. Next proposition is the counterpart to his result for the case of dixerentiated goods.

Proposition 4.2. Under Cournot competition, whenever the goods are not perfect substitutes, even drastic innovations are licensed.

Proof. Whenever ${ }^{\circ}<1 ; r_{c}<c^{M}$ holds. Therefore, under the optimal contract ..rm 2 produces a positive amount using the licensed technology.

Notice that this result is exactly the same we obtained for the Bertrand case, which seems to be counterintuitive because, given than Bertrand competition is more intense than Cournot, the patentee should be less interested in licensing under the former than under the latter. However, as above explained, under Bertrand competition the royalty allows the patentee to commit to a higher price. This collusive exect reduces competition, producing

\footnotetext{
${ }^{8}$ In fact, one exception does exist: when ${ }^{\circ}=0, r_{c}=0$ : In this particular case, the patentee faces the same problem as an external laboratory licensing the innovation to a monopoly. In that case, we know that the laboratory prefers a ..xed fee rather than a royalty (see K amien and Tauman, 1986).
} 
the result. In fact, it can be checked that the collusive exect is so important that it leads to a situation in which the third stage equilibrium prices under the optimal (unrestricted) royalty are higher, and thus outputs and social welfare lower under Bertrand than under Cournot competition. ${ }^{9}$ Indeed, as Proposition 3.3 has shown, in the former case, licensing may even reduce social welfare. As next proposition shows, however, under Cournot competition licensing cannot hurt social welfare.

Proposition 4.3. Under Cournot competition, licensing is always welfare improving.

Proof. As the optimal royalty never exceeds $c$, competition is never reduced under the optimal licensing contract. In the extreme case $r=c$, competition remains unchanged after the license is sold but industry et ciency (and social welfare) increase by the amount of the cost reduction produced by the use of the new technology, which is captured by the patentee.

The above result is a direct consequence of the fact that when ..rms choose quantities, the licensing revenues of the patentee do not depend on her choice of output, which implies that the royalty cannot be used by the patentee to commit herself to a less aggressive behavior in the market, as it happened when they chose prices and the patentee tied her licensing revenues to her third stage price decision. The reason is that under Cournot competition, the licensee's demand is not axected by the decision (on output) taken by the patentee.

\footnotetext{
${ }^{9} \mathrm{~N}$ otice that, in absence of licensing, equilibrium prices are lower under Bertrand than under Cournot competition (Vives(1985)).
} 


\section{CONCLUSION}

This paper shows that the optimal two-part tarix contract (a ..xed fee plus a linear per unit of output royalty) to license a cost reducing innovation to a rival ..rm may lead to a decrease in social welfare when the ..rms compete in prices (B ertrand) and not when they compete in quantities (Cournot). In particular, that may be the case when the goods are close enough substitutes and for intermediate (but not drastic) innovations. As we have shown, regardless of the type of competition, the optimal licensing contract always includes a positive royalty. While under both Cournot and Bertrand competition the royalty allows the patentee to soften ex-post competition by increasing the licensee's marginal cost by the amount of the royalty, under Bertrand it also allows her to commit to a higher price in the market stage, by strategically tying its choice of price to its previous decision on the royalty. This last exect is so important that it leads the equilibrium prices under the optimal unrestricted royalty to be higher, and thus social welfare lower, under Bertrand than under Cournot competition.

Our analysis relies on a number of restrictive assumptions. First, we consider the case of a duopolistic industry. Extending the model to an oligopoly with $n+1$.rms (the patentee and $\mathrm{n}$ potential licensees) would result in the patent holder being interested in licensing the innovation to only a fraction of all ..rms in the industry as a way to moderate ex-post competition and extract surplus not only from buyers but also from non-buyers by imposing them a negative externality: being a non-licensee implies producing with a relative higher cost with respect to licensees. For the case of an external patentee, this is by Kamien and Tauman (1986) and recently by Erutku and Richelle (2000). This generalization would make more likely to ..nd our result that licensing hurts social welfare, given that under the optimal contract only a fraction of ..rms would buy the innovation. Notice that, as we have shown in the paper, regardless of the type of competition, even drastic innovations are licensed to all ..rms (the only rival ..rm). Therefore, it is not a problem of lack of incentives to transfer the innovation what drives the result in our setting.

Second, we restrict ourselves to the analysis of linear two-part tarix contracts composed of a ..xed fee and a per unit of output royalty. This is, of course, restrictive. By enlarging 
the set of feasible licensing contracts to allow for more sophisticated licensing contracts, the pay-o obtained by the patentee would increase. Indeed, as Erutku and Richelle (2000) show for the case of an external patentee, by using contracts that include non-linear royalties based not only on output but on sales, an external patentee can always design a contract that allows her to collect the monopoly pro..ts and drives ..rms' pro.ts to zero, which implies that licensing small innovations reduces social welfare.

The fact that we restrict ourselves to the analysis of linear royalties based on the licensee's output, makes our main result about the possibility that licensing reduces welfare, even stronger that it would be if we considered a more general set of contracts. We have shown that in our simple setting it is not the complexity of the contracts which drives our main result on welfare. It is just the possibility that appears under Bertrand competition (and not under Cournot) of tying strategically the choice of the third stage strategic variable (price) to the previous decision on the royalty, which allows the ..rms to collude and explains the result. Observe that even in our restricted setting of linear royalties, we could achieve the same exect under Cournot competition by designing a linear royalty based not on the licensee's output, but on her sales. In that way, when choosing output in the third stage, the patentee would have an additional incentive to reduce it in order to increase market price, and thus the licensee's sales and her royalty revenues. 


\section{REFERENCES}

Arrow, K., 1962, Economic welfare and the allocation of resources for inventions, in The R ate and direction of inventive activity, ed. R. Nelson, Princeton, Princeton University Press.

Bousquet, A., Cremer, H., Ivaldi, M. and Wolkovicz, M., 1998, Risk sharing in licensing, International J ournal of Industrial Organization 16, 535-554.

Calvert, R., 1964, The encyclopedia of patent practice and invention management. New York: Reinhold.

E rutku, C., and Richelle, Y., 2000, O ptimal licensing contracts and the value of a patent, mimeo.

Hornsten, J., 1998, Signaling of innovation quality with licensing contracts, mimeo, Northwestern University.

Kamien, M. and Tauman, Y., 1984, The private value of a patent: a game theoretic analysis, J ournal of Economics (Supplement), 4, 93-118.

K amien, M . and Tauman, Y., 1986, Fees versus royalties and the private value of a patent, Quarterly J ournal of Economics, 101, 471-491.

Kamien, M., 1992, Patent Licensing. In: Aumann, R. J ., Hart, S. (eds), Handbook of Game Theory, chapter 11.

K atz, M. and Shapiro, C., 1985, On the licensing of innovations. Rand J ournal of Economics, $16,504-520$.

K atz, M. and Shapiro, C., 1986, How to license intangible property, Quarterly J ournal of Economics, 101, 567-590.

Macho-Stadler, I., Martínez-Giralt, X. and Pérez-Castrillo, D., 1996, The role of information in licensing contracts design, Research Policy 25, (1), 25-41.

M acho-Stadler, I. and Pérez-Castrillo, D ., 1991, Contrats de license et asymetrie d'information, Annales d'E conomie et de Statistique, vol 24, 189-208.

Muto, S., 1993, On licensing policies in Bertrand competition, Games and Economic Behavior 5, 257-267.

Rostocker, M., 1984, A survey of corporate licensing. IDEA, 24, 59-92. 
Singh, V. and V ives, X., 1984, Price and quantity competition in a dixerentiated duopoly, Rand J ournal of Economics 15, 546-554.

Taylor, C. and Silberston, Z., 1973, The economic impact of the patent system. Cambridge. Cambridge University Press.

Vives, $X ., 1985$, On the el ciency of Bertrand and Cournot equilibria with product differentiation, J ournal of Economic Theory, 34, 166-175.

Wang, X., 1998, Fees vs. royalty licensing in a Cournot duopoly model, Economics Letters 60, 55-62. 